\title{
Implementing Bloom's Taxonomy Tool for Better Learning Outcomes of PLC and Robotics Course
}

\author{
https://doi.org/10.3991/ijet.v15i05.12173 \\ Madhuri Gummineni \\ S R Engineering College, Warangal, India \\ madhuri.vijay2003@gmail.com
}

\begin{abstract}
Instrumentation subject has a major and vital role in the industrial field. The concepts of sensors, actuators, signal interface, and conditioning, programming the microprocessor and microcontroller are the most important requisites to comprehend and contribute for the real world application.The application of these concepts is PLC and Robotics course where the students can apply and practically experience the out- put. To design a project and to implement we need multidisciplinary concepts and sequence of steps viz., defining an idea, requirements and the fabricating parts to bring out a visual structure in order to perform an intended function. To inculcate this culture it's much more important to follow and implement the standard and well-known methodology called Bloom's taxonomy in the classroom environment for a better out- come of the course. Current leading technology PLC and Robotics course, (which require prerequisite knowledge of courses like Instrumentation, Microprocessors, and Mechatronics) are very well connected for applying the gained concepts to continue the stream of the learning process. The paper presents how to bring better learning Outcomes and also create interest in the course PLC and Robotics by implementing Bloom's taxonomy by conducting activities in the classroom.
\end{abstract}

Keywords-Mechatronics; Ladder Logic; Instrumentation; Multidisciplinary; Ideation.

\section{Introduction to Instrumentation}

The modern teaching imparted to the students of this era effects transformation towards higher order learning. Besides training the students to develop the ability to produce right answers, but an action plan is to be laid out to promote creativity and also develop independent and accustomed to making the students suitable for industries and entrepreneur skills. To deal with technological changes or challenges in the real world, as well as topics dealing with it, should be Open ended with multidisciplinary problems are cognitive and social imperatives.

Instrumentation is multidisciplinary in nature and has progressed within no time by co-working with peripheral technologies like communication, signal processing, and 
semiconductors, resulting in its applications in diverse fields like life sciences, environment measurement, industries and robotic.

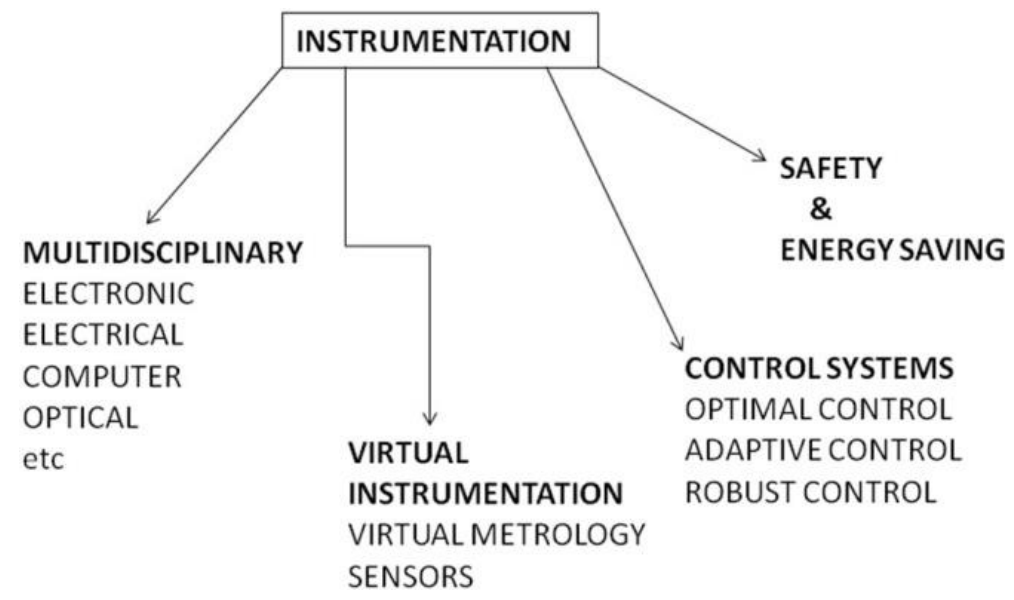

Fig. 1. Wide view of Instrumentation

\subsection{Motivation}

While teaching the current technology courses, it is most important to see whether the course also applies the concepts gained from prerequisites courses or not. A better stream flow is important, as well as balancing the application of concepts is also essential. The standard blooms taxonomy tool is simple and the most effective tool that can be implemented which brings out the required outcomes at each level of learning. We usually use blooms taxonomy only at the assessment stage, but the tool can also be implemented in stepwise to improve the outcomes of the course. In spite of Methods like project based learning, Adaptive methods, Bloom's taxonomy is very simple, standard and a proven effective tool to bring about qualitative and quantitative outcomes of the course. The stream flow of the subjects is as follows:

- Mechatronics (2year 2-semester)

- Control systems (3 year-1-semester)

- Microprocessors and Microcontrollers (3 year-1-semester)

- Electronics and Instrumentation (3year 2-semester)

- PLC and Robotics (4 year-1-semester)

Mechatronics: The Mechatronics course is set with an objective to acquire knowledge in order to automate a processor to control parameters of the system. Study of operations that are carried out in a sequence to automate the mechanical system(s) is called the sequential control. Programmable Logic Controller (PLCs) is an example of such a control system. 
Prerequisites: Mechatronics requires knowledge of the following subjects: Engineering mechanics, Electronic circuits analysis and design, Mathematics Calculus, differential equations, numerical methods, $\mathrm{C}$ programming.

Control Systems: The main objective of this course is to designing control schemes for dynamic systems. This course provides an understanding of the following topics like obtaining system response, analyze dynamic systems for their stability and performance, and design controllers (such as Proportional- Integral-Derivative) etc.

Microprocessor and Microcontrollers: This course will start with Un- derstanding the architecture of Microprocessors 8085 and extends in following any other complex CPU architecture. The course introduces concepts viz interfacing, Designing, integrating processors and apart from input-output ports, the peripherals also include timers, data converters, communication modules, and so on.

Prerequisites: Digital Electronics.

Electronics measurements and instrumentation (EMI): This course provides a way to understand Industrial Automation which includes Operation of Basic meters, measuring electrical quantities, transducers principle of operation and applications. Prerequisites: Network theory, Signals and system, Control system, Electrical machines.

PLC and Robotics: It is easier to create and change the program in PLC than to wire and rewire a circuit [1]. The end user can modify the program in the field. PLC can be networked to perform some functions as supervisory control, data gathering, monitoring devices, and process parameters.

Prerequisites: Mechatronics, Control Systems, Electronics measurements and instrumentation, Microprocessor and Microcontrollers, etc.

\subsection{Writing a new document with this template}

You may also simply delete all the text in this document, paste yours and format it with the styles.

\section{Bloom's Taxonomy Implementation in Teaching Engineering}

Engaging the students with a meaningful action plan by following a series of levels of learning is called Bloom's taxonomy which is a well-known pedagogy.

Fig. 2 shows the diagrammatic representation of taxonomy as it consists of six levels. The journey of learning starts from bottom to top.

Bloom's taxonomy helps to understand concepts in the easiest way and at this junction would like to acknowledge Benjamin Bloom's and Lorin Anderson. Blooms taxonomy is one of the ways of gauging competence in the world of learning and development. It basically consists of various levels and depths determine how well the student has understood a particular topic as well as determine the level to which the student belongs to. 


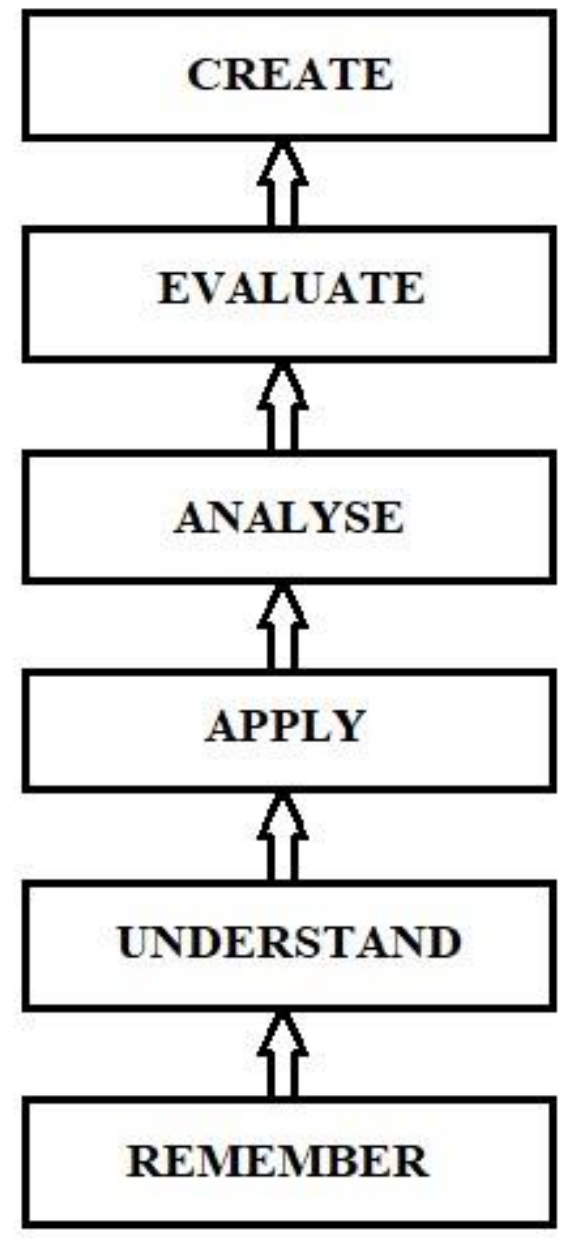

Fig. 2. Various levels of Blooms Taxonomy

The bloom's taxonomy action plans are as follows:

The previous semester subjects can be recalled, thus by applying blooms taxonomy, all the concepts that have been learned from the courses can be effectively utilized to apply and creatively think to develop new innovations which aid to the current scenario. 


\section{$3 \quad$ Methodology}

\subsection{Level 1 and 2 Implementation through Think Pair and Share: Unit 1-PLC Introduction:}

The ability to recall the facts, terms, and basic concepts relative to the subject like Mechatronics, Electronics and Instrumentation, Microprocessors and Microcontrollers. To implement this, the activity Think Pair Share Activity was conducted. Especially this activity has been chosen, for implementing two levels of blooms taxonomy, remember and understand the concept of Unit 1. If the students feel lag behind, during this activity or doubts while discussing with their peers helps them to fill the gaps that then helps them to gain more knowledge.

Steps in implementing think pair and share activity for assessment of level-1 and level-2 in bloom's taxonomy.

They have to choose any of the topics from Unit-1.

- Think: the student will think independently, and recall the concepts of topics.

- Pair: In Group Discussion they will share their thoughts and ideas with their partners.

- Share: Students share their ideas with the whole class.

This activity is conducted after the completion of unit 1 which includes introductory concepts, and review of various prerequisites essential for this course.

\subsection{Level 3: Implementation through seminar presentation from Unit-2 Ladder Logic Programming for Real-World Applications:}

After completion of unit 2, students will apply the concepts of ladder logic programming. The student needs to discuss with their teams and present one real- time application at that time with the teaching aids like Chalk and Board.

\subsection{Level 4 Implementation through Demo : Unit3: Introduction to Robotics:}

Demonstration of Biped Robot design with Arduino [3] and Servo Motors have made the students involve themselves with more interest in a practical demonstration. Therefore biped robot has demonstrated for motivating the students.

\subsection{Level 5 and 6 through Ideation Machine Vision and Design of Mechatronics Systems:}

Test conducted to present their own style of robot design [2]. Creativity thinking test has been conducted with an objective of adapting to the new environment for better performance. The test includes the following steps i.e. objective of the design of the new robot, requirements, and conclusion. Which are the most essential steps for implementing a project? Internal test 1 and 2 can be used to test their understanding 
and analysis of the gained concepts. Conducting an objective test can be one form of evaluating the outcome of course.

\section{$4 \quad$ Results and Discussion}

Table 1. Implementation of Blooms Taxonomy by performing various Activities

\begin{tabular}{|l|l|l|}
\hline \multicolumn{1}{|c|}{ Bloom's Level } & \multicolumn{1}{c|}{ Activity } & \multicolumn{1}{c|}{ Units } \\
\hline Remember & Think pair and share activity & Unit-1 PLC introduction \\
\hline Understand & Think pair and share activity & Unit-1 PLC introduction \\
\hline Apply & Presentation on real world problems & $\begin{array}{l}\text { Unit-2 Ladder logic programming for real } \\
\text { world applications }\end{array}$ \\
\hline Analyse & Team based learning activity & Robot introduction \\
\hline Evaluate & Objective test & Machine vision and design of Mechatronics \\
\hline Create & Ideation & Types of the robot \\
\hline
\end{tabular}

\subsection{Course outcomes}

At the end, of the course, the student will develop the ability to:

- Understand programmable logic controls.

- Select a suitable robot for a specific application.

- Discuss types of robots, robot dynamics, and their applications.

- Identify the importance of robot dynamics.

- Identify the suitable sensor and actuator for a control system.

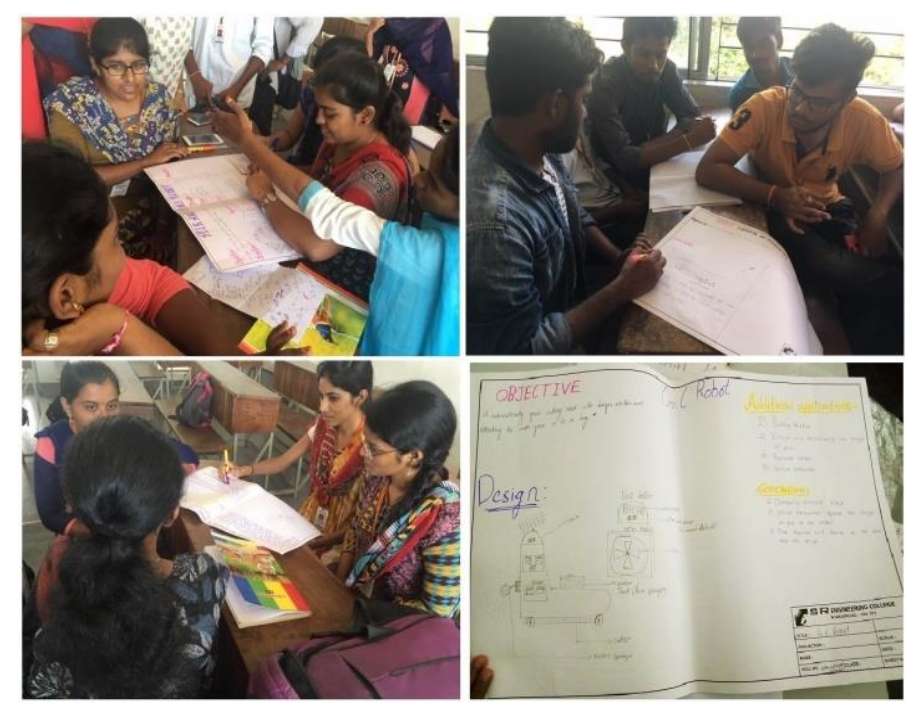

Fig. 3. Ideation activity in the classroom 


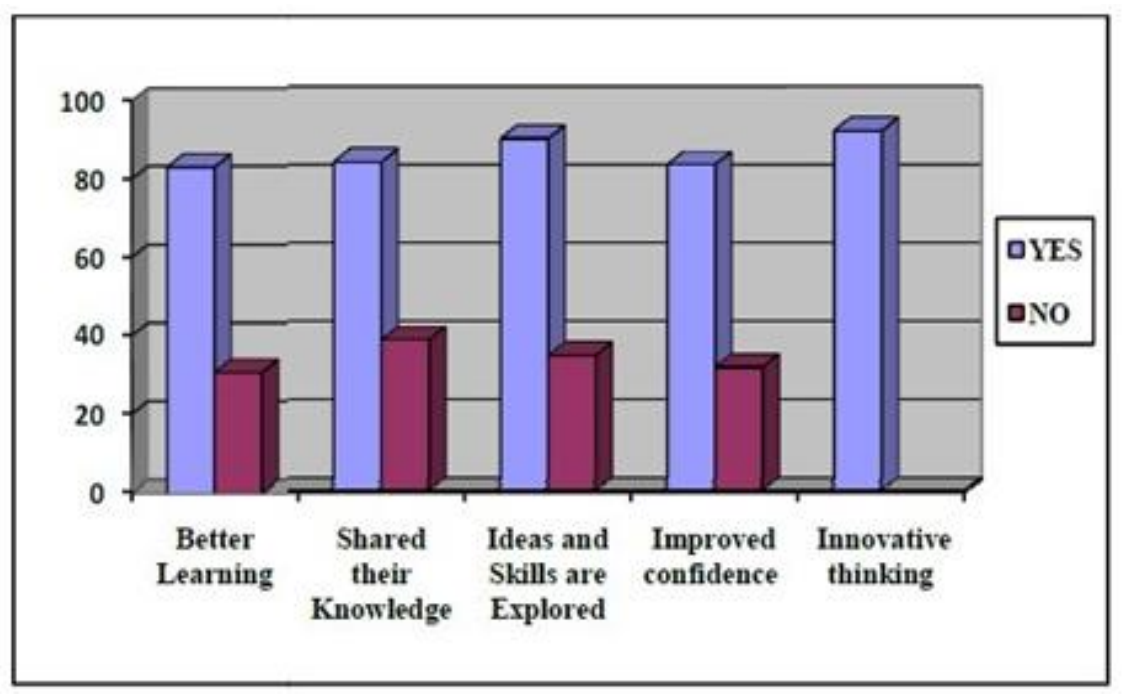

Fig. 4. Rubrics for the activities

\subsection{Inferences}

For each activity, the following Parameters are considered and evaluated.

i) Think pair share: From the unit -1 there are several concepts and basics that they need to recall and comprehend the importance of the subject. Certain topics have been highlighted, and on each topic, the team needs to discuss with their peers. First, they have to perform individually, and then they have to share with their pair.

While conducting this activity the following points are taken into consideration, for the assessment:

- Teamwork and individual Contribution

- Understanding / self-reporting when they don't understand

- Identify Alternatives (Other possible ways)

ii) Presentation: From unit-2 the ladder logic programming and various applications are presented by each team. The activity has conducted with the intended points that need to be assessed.

- Comprehensive (Present information in a Comprehensive manner)

- Communication Skills

- Speak Effectively and Accurately.

iii) Team-Based Learning: For each team, the real-time problems are given while mentoring the students; each team shares their solutions with the mentor and after final discussion and concludes the solution and each team present it before the whole class. 
- Attitude and involvement

- Contribution (playing leadership role)

- The procedure laid by the team

- Coordinating, self-motivating and professionalism

iv) Ideation: During this activity, the students will follow the steps: The fore- most steps is to define the main objective of the new robotic design. The following steps are the structure of the robot, Requirements for implementing the Design, Cost of manufacturing, Time to Market, and application of robot. The assessment for this activity includes.

- Creative Thinking: Imaginative ideas, unique perspectives, innovative strategies, or novel (alternative).

- Multiple Perspective: Variety of viewpoints, standpoints, or positions, to gain a more comprehensive and holistic understanding etc.

- Balanced Thinking: Consider arguments/evidence for and against a particular position or viewpoint

\section{Conclusion}

The bloom's taxonomy tool effectively worked in the classroom environment and improved the outcomes like understanding the concepts; applications of the knowledge acquired and improve confidence in the students.

\section{Acknowledgement}

With profound gratitude, I would like to express my heartiest thanks to Dr. J. Tarun Kumar Head of Department ECE and Dr. P. V. Raja Shekar Head Center for Creative Cognition for their continuous support. I would like to extend my esteemed thanks to our principal Dr. V. Mahesh and also grateful to our Management for their encouragement towards the implementation of best teaching and learning practices.

\section{$7 \quad$ References}

[1] Dimitris Alimisis: "Educational robotics: Open questions and new challenges". Themes in Science \& Technology Education, 6(1), 63-71, 2013.

[2] Omar Mubin, Catherine J. Stevens, Suleman Shahid, Abdullah Al Mahmud, and Jian-Jie Dong: "A review of the applicability of Robots in education". Technology for Education and Learning, 2013. https://doi.org/10.2316/journal.209.2013.1.209-0015

[3] Christina Chalmers: "Preparing Teachers to Teach STEM through Robotics". In- ternational Journal of Innovation in Science and Mathematics Education, 25(4), 1731, 2017. 


\section{Author}

Mrs. Gummineni Madhuri Pursuing Ph. D in GITAM Deemed to be University, Hyderabad Campus, and working as Assistant Professor in S R Engineering College, Warangal, Telangana, India. Received B. Tech in E\&IE from JNTU, Hyderabad and Post Graduated M. Tech in Digital Systems and Computer Electronics from JNTU, Hyderabad. (Email: madhuri.vijay2003@gmail.com \& vijayieee.2013@gmail.com)

Article submitted 2019-11-02. Resubmitted 2019-12-16. Final acceptance 2019-12-19. Final version published as submitted by the authors. 